rund 39\% der verabreichten Phenacetin-Dosis als konjugiertes bzw. nicht-konjugiertes NAPAP mit der angegebenen Methode als p-Aminophenol erfaßt werden. Aus Tabelle 2 geht hervor, daß 6 Stunden nach Verabreichung von NAPAP sich in einem mittleren Harnvolumen von $252 \mathrm{~m} l$ rund $27 \%$ der verabreichten Dosis $(2 \mathrm{~g})$ mit der neuen Methode auffinden lassen. Da 20 $\mathrm{mg} \%$ p-Aminophenol im Harn quantitativ, $1 \mathrm{mg} \%$ noch qualitativ erfaßbar sind, ergibt sich, daß therapeutische Einzeldosen von $200-600 \mathrm{mg}$ Phenacetin bzw. NAPAP bis zu 12 Stunden nach Einnahme bestimmbar, bis zu 48 Stunden nach Einnahme nachweisbar sind. In allen Urinproben war nach Gabe von Phenacetin außerdem das gelbe Phenoxazon-Derivat nachweisbar.

Somit liegt eine Methode vor, die es gestattet, unter Zuhilfenahme der Dünnschichtchromatographie und der Spektrophotometrie sichere Angaben über die Einnahme von Phenacetin oder NAPAP zu machen. Bei einer Intoxikation mit diesen Analgetica läßt sich durch quantitative Bestimmung im 24-Stunden-Urin über mehrere Tage und Addition der gemessenen p-Aminophenol-Mengen die eingenommene NAPAP- oder Phenacetin-Dosis ziemlich genau ermitteln. Bei derartigen Bilanzuntersuchungen muß nach PhenacetinEinnahme berücksichtigt werden, daß die Ausscheidung an p-Äthoxy-o-sulfonyloxy-anilin in 8 Stunden rund $8 \%$ - bezogen auf die eingenommene Dosis - beträgt (7). Dagegen kann man die Ausscheidung von unverändertem Phenacetin und von p-Phenetidin - zusammen $<1 \%$, bezogen auf die eingenommene Dosis - die die p-Aminophenol-Bestimmung ebenfalls nicht erfaßt, vernachlässigen.

\title{
Literatur
}

1. Brodie, B. B. und J. Axelrod, J. Pharmacol. exp. Therapeut. 97, 58 (1949). - 2. SMith, J. N. und R. T. WiLLIAMs, Biochem. J. 44, 239 (1949). - 3. Pfleger, K., W. Rummel, E. Seifen und H. BleICHER, Arch. int. Pharmacodynam. Thérap. 134, 467 (1961). - 4. Clausen, E. und O. A. Larsen, Acta pahrmacol. toxicol. (København) 22, 135 (1965). - 5. Brodie, B. B. und J. Axelrod,
J. Pharmacol. exp. Therapeut. 94, $22 \cdot(1948)$. - 6. STAHL E., Dünnschichtchromatographie, S, 7-10, Springer-Verlag BerlinGöttingen-Heidelberg (1962). - 7. BücH, H., H. HäUSER, K. Pfleger und W. Rüpiger, Naunyn-Schmiedebergs Arch. exp. Pathol. Pharmakol. 253, 25 (1966). - 8. Büch, H., H. HÄUSER, K. PFLeger und W. RüDIGER (in Vorbereitung).

\section{Mikromethode zur quantitativen Chloridbestimmung}

\author{
Von F. C. StTzManN \\ Aus der Universitätskinderklinik Erlangen-Nürnberg (Direktor: Prof. Dr. A. Windorfer)
}

(Eingegangen am 23. Dezember 1965)

\begin{abstract}
Es wird über eine einfache, rasche und genaue Mikromethode zur Chloridbestimmung in Serum, Schweiß und Urin berichtet. Die Methode beruht auf der photometrischen Messung der durch Chlorionen freigesetzten Chloranilsäure aus Quecksilberchloranilat im sauren Medium. Die Zuverlässigkeit der Methode wurde überprüft. Die gefundenen Normalwerte liegen durch die Enteiweißung des Serums niedriger ( $81-103 \mathrm{mval} / \mathrm{l})$. Wegen der geringen Untersuchungsmenge kann diese Methode für die Kinderklinik empfohlen werden.

A simple, rapid and precise micromethod for the determination of chloride in serum, sweat and urine is described. The method is based on the photometric measurement of chloranilic acid, which is formed from mercury chloranilate in the presence of chloride ions in acid media. The reliability of the method is discussed. The method is recommended for the pediatric clinic, because the necessary amount of serum is small; the normal value, found by this method, is $81-103$ meq. $/ l$.
\end{abstract}

Die für quantitative Bestimmungen notwendigen Serummengen stehen in der Kinderklinik nicht immer zur Verfügung; bei Frühgeborenen und jungen Säuglingen bereitet ihre Gewinnung oft erhebliche Schwierigkeiten. Andererseits verlangen die Stoffwechselstörungen in dieser Altersklasse einen genauen Blick in die vorliegende Ionenverschiebung. Man sucht besonders in der Kinderheilkunde daher nach Mikro- und Ultramikromethoden. Auch zur Chloriduntersuchung im Schweiß, einer wichtigen Methode zur Diagnose der Mucoviscidose, wird man sich einer Mikromethode bedienen müssen, da die gewonnenen Schweißmengen oft unter $0,5 \mathrm{~m} l$ liegen (1). Bisher entwickelte Mikro- und Ultramikromethoden, die wir auch RichTERICH (2) verdanken, haben sich gut eingeführt und im Labor bewährt.
BARNEY (3) und BertolacinI (4) haben 1957 vorgeschlagen, die Chlorionen in der Reaktion mit dem Silbersalz der Chloranilsäure zu bestimmen. Die auf diese Weise freigesetzte Chloranilsäure wird dann photometrisch gemessen. BAZINSKI und Mitarbeiter (5) haben die Chloridbestimmung nach diesem Reaktionsschema in großen Untersuchungsreihen durchgeführt. Dabei wurde jedoch das Quecksilbersalz der Chloranilsäure genommen, da das entstehende Quecksilberchlorid nur wenig dissoziiert (modifizierte Methode nach LANG (6)). $\mathrm{Da}$ hierbei auch bei sehr wenig Untersuchungsmaterial zuverlässige Werte erhalten werden, haben wir diese Methode überprüft und vergleichende Untersuchungen mit der von uns bisher angewandten Methode vorgenommen, wobei die elektrometrische Titration mit 
Tab. 1: Arbeitsvorschrift für die Chloridbestimmung

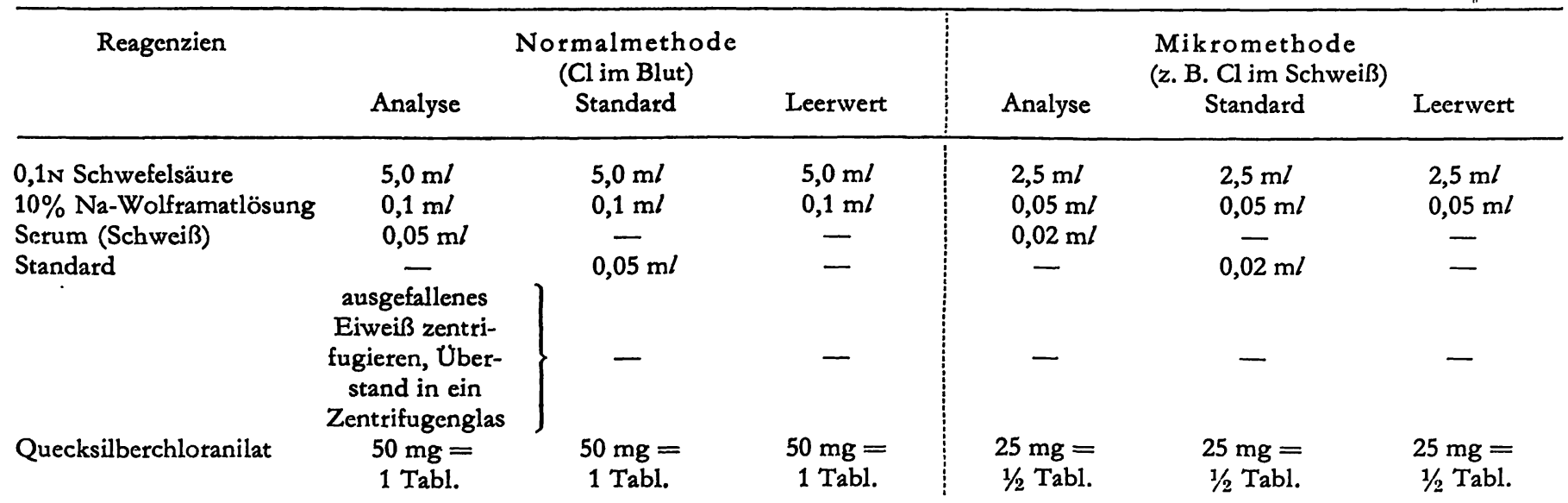

15 Min. warten, 1 Min. schütteln, 10 Min. zentrifugieren bei 3000 U/Min., filtrieren durch Faltenfilter, in die $10 \mathrm{~mm}-\mathrm{Küvette} \mathrm{gießen.}$ Dann gegen Leerwert ablesen.

Silbernitrat angewandt wurde (7). Unter Verwendung einer Silberelektrode wurde Chlor mit Silbernitrat direkt titriert. Eine Enteiweißung brauchte nicht vorgenommen werden.

\section{Methode}

Für jede Chloridanalyse wird ein Reagenzienleerwert und ein Standardwert angesetzt, deren Zusammensetzung in der Tabelle 1 angegeben ist.

\section{Ansatz fiir die Analyse}

In ein Spitzglas werden $5 \mathrm{ml} 0,1 \mathrm{~N}_{2} \mathrm{SO}_{4}$ gegeben, $0,1 \mathrm{ml}$ 10-proz. Natriumwolframatlösg., sowie $0,05 \mathrm{~m} l$ Serum (Natriumwolframatlösung wird als gebrauchsfertige Lösung geliefert $\left.{ }^{1}\right)$. Das nun ausgefällte Eiweiß wird scharf abzentrifugiert (5 Min. 3000 U/Min.) und der klare Uberstand in ein Zentrifugenglas abgegossen. Zu diesem Uberstand werden $50 \mathrm{mg}$ Quecksilberchloranilat ${ }^{1}$ ) (=1 Tablette) gegeben, sodann 1 Min. kräftig geschüttelt, 15. Min gewartet und wiederum zentrifugiert (10 Min. b. 3000 U/Min.). Der Úberstand wird durch ein Faltenfilter in die Küvette $(d=1 \mathrm{~cm})$ gegossen und die Extinktion bei $510-560 \mathrm{~m} \mu$ (Elko II und III Filter S 53 E) gegen den Leerwert gemessen. Man erhält so die Extinktion E (A).

\section{Ansatz fïr den Standardwert}

In ein Reagenzglas werden die gleichen Mengen 0,1 $\mathrm{N}_{2} \mathrm{SO}_{4}$ und 10-proz. Natriumwolframatlösg. gegeben, anstelle des Serums aber $0,05 \mathrm{ml}$ Standardlösung ${ }^{2}$ ), die auch als gebrauchsfertiges Reagenz geliefert wird. Ës enthält $0,1 \mathrm{~N} \mathrm{KCl}(100 \mathrm{mval} / l)$. $\mathrm{Da}$ es zu keiner Eiweißfällung kommt, ist ein Zentrifugieren nicht notwendig. Es kann sofort das Chloridreagenz (Quecksilberchloranilat = $50 \mathrm{mg}$ ) zugegeben werden. Die weitere Verarbeitung gleicht der für den Analysenansatz. Bei der gleichen Wellenlänge wird in der Küvette $(\mathrm{d}=1 \mathrm{~cm})$ der Extinktionswert $\mathrm{E}(\mathrm{S})$ gegen den Leerwert $\mathrm{ab}$ gelesen.

\section{Ansatz für den Leerwert}

Der Reagenzienleerwert bestaht aus $5 \mathrm{ml} 0,1 \mathrm{~N}_{2} \mathrm{SO}_{4}, 0,1 \mathrm{~m} l$ 10-proz. Natriumwolframatlösg. und $50 \mathrm{mg}(=1 \mathrm{Tab}$.) Quecksilberchloranilat. Die Ablesung erfolgt in der Küvette $(\mathrm{d}=1 \mathrm{~cm})$ bei $510-560 \mathrm{~m} \mu$ züsammen mit dem Analysen- bzw. Standardansatz

\section{Berechnung:}

$$
\frac{\text { Extinktion Analyse (E A) }}{\text { Extinktion Standard (E S) }} \times 100=\mathrm{mval} / \mathrm{l}
$$

1) Die Reagenzien sind in Testpackungen der chem. Fabrik Dr. H. Haury, 8 München 23 im Handel. Für die Überlassung von Probepackungen danken wir der Firma.

2) Diese kann von der Fa. Dr. Haury bezogen werden.
Die abgelesene Extinktion des Leerwertes braucht in der Berechnung nicht berücksichtigt zu werden, wenn man den Analysen- und Standardansatz gegen den Leerwert mißt. Zur rascheren Ablesung kann eine bewegliche Eichkurve, bei der die Extinktion des Standardwertes jeweils einzustellen ist, empfohlen werden ${ }^{1}$ ).

Die gleiche Methode kann auch zur Untersuchung des Schweißes angewandt werden. Die Analysenmenge kann auf $0,02 \mathrm{ml}$ (!) reduziert werden; es muß jedoch dann auch die $0,1 \mathrm{~N}$ Schwefelsäure auf $2,5 \mathrm{ml}$ verringert werden, die Natriumwolframatlösung (10\%) auf 0,05 ml. Im Standardansatz wird die Menge des Chlorid-Standardreagenzes nur $0,02 \mathrm{ml}$ betragen und zu allen $3 \mathrm{An}$ sätzen (Analyse-, Standard-, Leerwert) auch nur eine halbe Quecksilberchloranilat-Tablette gegeben. Somit bleibt die Berechnungsformel gleich.

Auch zur Chloridbestimmung im Urin kann die Methode herangezogen werden (8). Dabei wird vor Ansatz der Urin im Verhältnis 1:1 verdünnt; die Arbeitsweise ist sonst die gleiche. Diese Verdünnung muß in der Endberechnung berücksichtigt werden, indem das Ergebnis wieder mit 2 multipliziert wird.

\section{Diskussion}

Die beschriebene Methode beruht auf der Tatsache, daß aus dem wasserunlöslichen Quecksilberchloranilat im sauren Medium durch Anionen, hier die Chloridionen des Serums, Chloranilsäure freigesetzt wird (6). Die violett-purpurne Chloranilsäure, die der Menge des im Serum vorhandenen Chlorids proportional ist, wird photometrisch gemessen.

In dieser Arbeitsvorschrift wird durch Natriumwolframat zusätzlich eine Eiweißfällung durchgeführt, da wegen der Bindung des Quecksilbers an das im Serum enthaltene Eiweiß zuviel Chloranilsäure freigesetzt und so ein zu hoher Chloridgehalt vorgetäuscht wird, worauf FüHR (9) hinweist. Eigene vergleichende Untersuchungen mehrerer Chloridbestimmungen im Serum ohne und mit Enteiweißung ergaben dies deutlich. Die gewonnenen Chloridwerte sind um 12-20 mval/l höher als im nicht enteiweißten Serum.

Das entstandene Metallsalz ist ebensowenig dissoziiert wie das Metallchloranilat und stört bei der Messung nicht. Bei der Bestimmung des Chlorids mit Silberverbindun- 
gen entsteht kolloidales Silberchlorid, dessen Entfernung schwierig ist $(9,10)$.

Die Durchführung dieser Chloridbestimmung ist einfach. Durch die auf ein Minimum reduzierten Pipettierungen werden Fehlerquellen ausgeschlossen - außerdem auch dadurch, daß die genannten Reagenzien in Testpackungen ansatzfertig bezogen werden können. Falls bei jungen Säuglingen und Frühgeborenen auch die Menge von $0,05 \mathrm{~m} l$ nicht entnommen werden kann, so genügen $0,02 \mathrm{~m} l$, entsprechend der Anleitung in Tabelle 1. Dabei wäre eine Venenpunktion nicht erforderlich, da man derartig geringe Serummengen auch durch einen Schnepperstich aus Ferse, Fingerbeere oder Ohrläppchen gewinnen kann, worauf wir schon früher hingewiesen haben (11).

Es ist darauf zu achten, daß die Tablette $\mathrm{Hg}$-Chloranilat vollständig zerfällt, evtl. muß man mit einem Glasstab nachhelfen (nach Zugabe der $\mathrm{Hg}$-Chloranilattablette wartet man 15-20 Min. bis die Tablette vollständig aufgelöst ist und rührt mit einem Glasstab kräftig um). RENSCHLER (10) hat festgestellt, daß die Extinktion doch von der zugesetzten Menge an $\mathrm{Hg}$-Chloranilat abhängt. $\mathrm{Da}$ bei dieser Methode das $\mathrm{Hg}$-Chloranilat bereits in Tablettenform konstante Mengen von $50 \mathrm{mg}$ enthält, fällt somit eine weitere Fehlerquelle weg und der Arbeitsvorgang wird dadurch erleichtert, daß man das Reagenz nicht abwiegen muß. Störungen dieser Methode können durch Kationen (besonders $\mathrm{Fe}^{+++}, \mathrm{Cu}^{++}$, $\left.\mathrm{Pb}++, \mathrm{Ca}^{++}\right)$und durch Anionen $\left(\mathrm{PO}_{4}^{--}, \mathrm{Br}^{-}, \mathrm{BrO}_{3}^{-}\right.$, $\left.\mathrm{J}^{-}\right)$verursacht werden, was vor allem BARNEY und Mitarbeiter (3), sowie BergmanN und Mitarbeiter (12) untersuchten; der Fehler beträgt aber weniger als $1 \%$. Die zu messende Extinktion der freigesetzten Chloranilsäure bei einer Wellenlänge von $510-560 \mathrm{~m} \mu$ beruht darauf, daß diese Säure 2 Absorptionsmaxima aufweist, und zwar ein hohes schmalbasiges bei $305 \mathrm{~m} \mu$ und ein flaches breitbasiges bei $580 \mathrm{~m} \mu$ (Abb. 1), das für die Messung verwendet wird. Die Farbintensität ist proportional der Konzentration des gesuchten Chloridions; sie bleibt nach unseren wiederholten Untersuchungen 4 Stdn. konstant und steigt nach 5-8 Stdn. erst langsam um $1-3 \%$ an, was nur $1-2 \mathrm{mval} / \mathrm{l} \mathrm{Cl}$ ausmacht. Die gewonnenen Normalwerte liegen bei der Chloridbestimmung mit Enteiweißung mit dieser Methode zwischen 81-103 mval $/ \mathrm{l}$ im Serum.

Wiederholte 10fache Bestimmungen aus dem gleichen Serum ergaben eine Standardabweichung des Mittel-

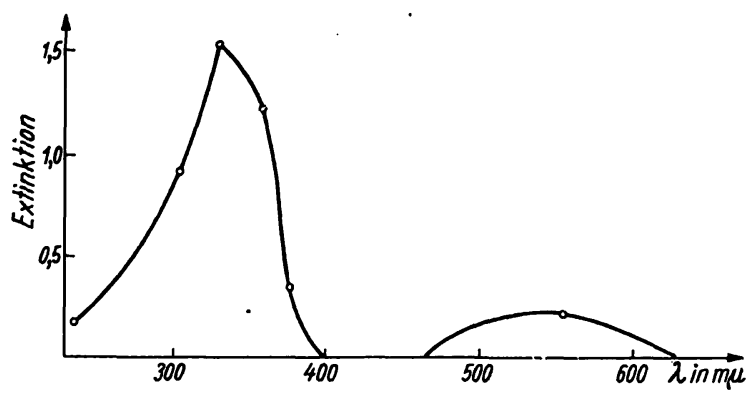

Abb. 1

Absorptionsspektrum der Chloranilsäure nach BaRNEY und Mitarbeiter (3)

wertes von $\pm 0,52 \mathrm{mval} / l$ bei enteiweißtem und $\pm 1,3$ bei nicht enteiweißtem Serum. Wir haben diese Chloridbestimmungsmethode mit Lab-TROL ${ }^{1}$ ) und Versatol $\left.A^{1}\right)$, die eine bekannte Chloridkonzentration enthalten, in verschiedenen Verdünnungen kontrolliert (13). In Tabelle 2 sind die Ergebnisse dargestellt; sie zeigen eine gute Übereinstimmung. Außerdem wurde die Methode mit der bisher durchgeführten Titrationsmethode verglichen. Es zeigten sich dabei konstante Abweichungen $z$ wischen 5-11 mval $/ l$, die mit der vorgenommenen Enteiweißung zu erklären sind.

Tab. 2

Wiederfindung von Chlorid in Kontrollseren mit bekanntem Chlorid-Gehalt (Werte in mval/l)

\begin{tabular}{|c|c|c|c|}
\hline \multicolumn{2}{|c|}{ Versatol-A } & \multicolumn{2}{|c|}{ Lab-TROL } \\
\hline $\begin{array}{l}\text { im Ansatz } \\
\text { enthalten }\end{array}$ & $\begin{array}{l}\text { wieder- } \\
\text { gefunden }\end{array}$ & $\begin{array}{l}\text { im Ansatz } \\
\text { enthalten }\end{array}$ & $\begin{array}{l}\text { wieder- } \\
\text { gefunden }\end{array}$ \\
\hline 88,70 & 86,70 & 104,00 & 101,00 \\
\hline 44,35 & 44,00 & 52,00 & 49,14 \\
\hline 22,17 & 22,10 & 26,00 & 25,76 \\
\hline 11,00 & 10,82 & 13,00 & 12,00 \\
\hline 5,50 & 5,40 & 6,50 & 6,31 \\
\hline 2,25 & 2,20 & 3,25 & 3,20 \\
\hline
\end{tabular}

Die beschriebene Bestimmungsmethode hat sich uns als genaue, rasch auszuführende und einfache Arbeitsweise erwiesen und ist wegen der geringen Menge Ausgangsmaterial (Serum, Schweiß, Urin) für das Labor der Kinderklinik von Bedeutung.

Frl. HARTMANN danke ich für die zuverlässige Mitarbeit.

1) Lab-TROL: Alleinvertrieb in Deutschland: Asid-Institut GmbH, 8 München 13.

Versatol A: Gödecke \& Co., Chem. Fabrik-AG. Freiburg/Brg.

\section{Literatur}

1. Косн, E., H. BoHN und $F_{R}$. Косн, Mucoviscidosis, Zystische Pankreasfibrose Symp. 20. 9. 1962 in Gießen, F. K. Schattauer-Verlag, Stuttgart (1964). - 2. Richterich, R. und K. LAUBER, Klin. Wschr. 40, 1252 (1962). - 3. BARNEY, J. E. und R. I. BERtolacinr, Aralytic. Chem. 29, 1187 (1957). - 4. Bèrtolacinr, R. I. und J. E. Barney, Analytic. Chem. 29, 281 (1957). - 5. BAzinYKY, E. S., LA. Williams, Th. Jarkowsky und B. Zak, Amer. J. clin. Pathol. 30, 559 (1957). - 6. LANG, K., Biochem. Z. 290, 289
(1937). - 7. Sanderson, P. H., Biochem. J. 52, 502 (1952). 8. Kuschinsky, G. und H. Langecker, Biochem. Z. 318, 164 (1948). - 9. FüHR, J., Med. Mschr., Stuttgatt 18, 230 (1964). 10. Renschler, H. E., Klin. Wschr. 40, 484 (1962). - 11. SirzmanN, F. C., Klin. Wschr. 42, 1030 (1965). - 12. BergmanN, I. G. und J. SANIK jr., Analytic. Chem. 29, 241 (1957). - 13. SснöN, H., Årztl. Laborat. 3, 397 (1957).

\footnotetext{
Dr. F. C. Sitzmann, Univ.-Kinderklinik Erlangen-Nürnberg 852 Erlangen, Loschgestraße 15
} 